\title{
Study on direct current reactive sputtering deposition of aluminum nitride thin films
}

F. C. Stedile, I. J. R. Baumvol, W. H. Schreiner, and F. L. Freire

Citation: Journal of Vacuum Science \& Technology A 10, 3272 (1992); doi: 10.1116/1.577854

View online: https://doi.org/10.1116/1.577854

View Table of Contents: https://avs.scitation.org/toc/jva/10/5

Published by the American Vacuum Society

\section{ARTICLES YOU MAY BE INTERESTED IN}

Stress and piezoelectric properties of aluminum nitride thin films deposited onto metal electrodes by pulsed direct current reactive sputtering

Journal of Applied Physics 89, 6389 (2001); https://doi.org/10.1063/1.1359162

Properties of aluminum nitride thin films for piezoelectric transducers and microwave filter applications Applied Physics Letters 74, 3032 (1999); https://doi.org/10.1063/1.124055

Structural characteristics of AIN films deposited by pulsed laser deposition and reactive magnetron sputtering: A comparative study

Journal of Vacuum Science \& Technology A 16, 2804 (1998); https://doi.org/10.1116/1.581425

GaN, AIN, and InN: A review

Journal of Vacuum Science \& Technology B: Microelectronics and Nanometer Structures Processing, Measurement, and Phenomena 10, 1237 (1992); https://doi.org/10.1116/1.585897

Preparation of aluminum nitride thin films by reactive sputtering and their applications to $\mathrm{GHz}$-band surface acoustic wave devices

Applied Physics Letters 64, 166 (1994); https://doi.org/10.1063/1.111553

Impact of magnetron configuration on plasma and film properties of sputtered aluminum nitride thin films Journal of Applied Physics 104, 063301 (2008); https://doi.org/10.1063/1.2978226

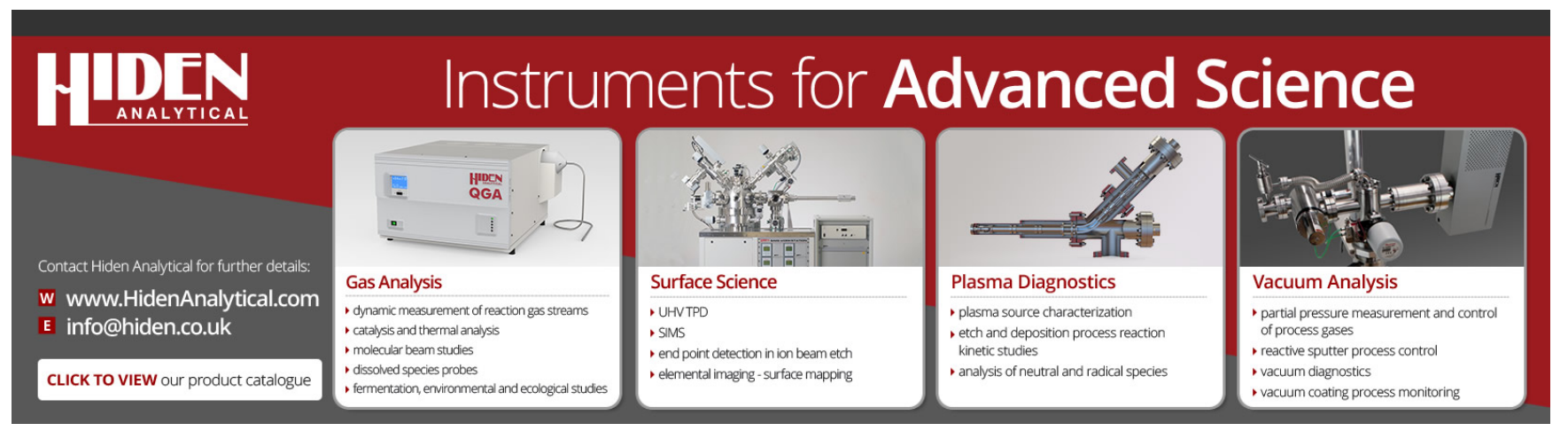




\title{
Study on direct current reactive sputtering deposition of aluminum nitride thin films
}

\author{
F. C. Stedile \\ Instituto de Quimica, Universidade Federal do Rio Grande do Sul, 91500, Porto Alegre, RS, Brazil \\ I. J. R. Baumvol and W. H. Schreiner \\ Instituto de Fisica, Universidade Federal do Rio Grande do Sul, 91500, Porto Alegre, RS, Brazil \\ F. L. Freire, Jr. \\ Departamento de Fisica, Pontificia Universidade Católica do Rio de Janeiro, 22452, \\ Rio de Janeiro, RJ, Brazil
}

(Received 31 December 1991; accepted 30 May 1992)

\begin{abstract}
Aluminum nitride thin films were deposited by dc magnetron reactive sputtering. The deposition parameters (cathode voltage, incident power, total pressure, and $\mathbf{N}_{2}$ partial pressure) were correlated and their influences on the compositional properties of the films were determined. The analytical tools used to characterize the aluminum nitride thin films were Rutherford backscattering spectrometry and the $(d, p)$ and $(p, \gamma)$ nuclear reactions. From these techniques the thickness and stoichiometric ratio N/Al of the films, the $\mathrm{N}$ and $\mathrm{Al}$ depth profiles, and the contamination levels of $\mathrm{O}$ and $\mathrm{C}$ were obtained.
\end{abstract}

\section{INTRODUCTION}

Aluminum nitride thin films have found widespread applications in recent years due to their properties such as high hardness, low electrical conductivity, good chemical stability, and so on. Owing to the high acoustic velocity and large piezoelectric coupling factor of the wurtzitestructured AlN films, they have been used for the generation and detection of surface acoustic waves. ${ }^{1}$ In particular, aluminum nitride has very interesting applications in microelectronic devices. AlN is a III-V compound with a large energy band gap, good thermal conductivity, stability up to very high temperatures, and chemical inertness. One of its uses is as an insulator in some metal-insulatorsemiconductor (MIS) structures (Al-AlN-Si for example). ${ }^{2}$ Another application in semiconductor technology is the use of AlN films as cap layers for GaAs. The presence of a cap is required when the GaAs wafer is submitted to high-temperature annealings $\left(T>800^{\circ} \mathrm{C}\right)$ during the fabrication of integrated circuits. This cap should prevent As evaporation and dopant outdiffusion and also minimize the stress in the cap-semiconductor interface. Aluminum nitride films have exhibited superior performance in all these aspects when compared to $\mathrm{SiO}_{2}$ and $\mathrm{Si}_{3} \mathrm{~N}_{4}{ }^{3}$

Aluminum nitride films have been deposited by various methods such as chemical-vapor deposition, ${ }^{4}$ reactive evaporation, ${ }^{5}$ reactive molecular-beam epitaxy, ${ }^{6}$ ion plating, ${ }^{7}$ ion implantation, ${ }^{8}$ ion-beam-assisted deposition, ${ }^{9}$ dual ion-beam deposition, ${ }^{10}$ and reactive sputtering. ${ }^{1,3,11}$ Each method leads to films with different compositional, structural, and mechanical characteristics. The choice of one particular deposition method depends on the features required for the specific application that one has in mind. If it is desirable to avoid high temperatures of the substrate and the hydrogen incorporation during deposition and to minimize the contamination level with other gaseous species the deposition of aluminum nitride films by magnetron reactive sputtering is a good choice, since the secondary electrons are confined by the magnet and cannot heat the substrate and we can obtain a clean (basically $\mathrm{Ar}$ and $\mathrm{N}_{2}$ ) and controlled (monitoring with a quadrupole mass spectrometer) atmosphere in the deposition chamber.

The reactive sputtering method itself was studied by various authors, among them Berg et al. ${ }^{12}$ During depositions of titanium nitride films, Berg et al. noticed the presence of hysteresis loops when they made graphs of the sputtering rate and nitrogen partial pressure versus the nitrogen flow and related them to situations of rapid transitions occurring during the nitridation and denitridation of the target. In Ref. 12 these authors proposed a mathematical model to describe the process. The explanation they gave abandoned the commonly accepted idea of a "critical pressure" and, instead, worked only with well-known physical properties such as flow, ion current density, sputtering yield, sticking coefficients, and others. Previous to the work of Berg et al., Maniv and Westwood ${ }^{13,14}$ were the first to investigate the reasons for hysteresis in reactive sputtering. McMahon, Affinito, and Parsons ${ }^{15}$ and Affinito and Parsons, ${ }^{16}$ on the other hand, were the first to explore the problems of reproducibility in reactive sputtering deposition of thin films, introducing an earlier model also based on physical properties. In Ref. 15 various operating modes in the deposition of $\mathrm{AlN}_{x}$ thin films by dc reactive sputtering were investigated. Rapid transitions between the metallic and nitrided target situations were observed when they controlled the gas flow rates at constant power and when they controlled the power at constant flow rates. However, by means of controlling the voltage at constant flow rates they could obtain experimental points inside the instability region and neither hysteresis nor sharp transitions were observed.

In the present work we deposited $\mathrm{AlN}_{x}$ thin films by dc magnetron reactive sputtering under different conditions of $\mathrm{N}_{2}$ partial pressure, total pressure, and incident power. We 
studied the correlations among the deposition parameters and we could relate them to the compositional characteristics of the films. The thicknesses and stoichiometries of the films were determined by nuclear reaction analyses and by Rutherford backscattering spectrometry.

\section{EXPERIMENTAL DETAILS}

The aluminum nitride thin films were deposited in a Balzers BAS-450 magnetron sputtering system equiped with a feedback mechanism to maintain the pressure at a constant level. The gas inlet was automatically regulated by a valve control unit that maintained a constant predetermined pressure inside the chamber with the pumps operating. One of the instruments used to monitor the process was an ionization vacuum gauge that measured the total pressure in the range of $10^{2}-10^{-4} \mathrm{~Pa}$. Since each gas flow could be switched on and off independently we could measure the pressure of Ar and $\mathrm{N}_{2}$ separetely and then let both gases flow together. The pressure-dependent ion current of a hot-cathode gauge head was used for the measurements. The measured ion current was converted into a corresponding voltage by an electrometer amplifier and displayed on the indicating instrument. The emission current was held constant by a control circuit. The ion current was then proportional to the pressure within the measuring gauge. Another apparatus we used to control the total and partial pressures of the gases was a quadrupole mass spectrometer for the mass range 0.5-64 amu. Its lowest- and upper-pressure limits of operation were $1 \times 10^{-8}$ and $1 \times 10^{-1} \mathrm{~Pa}$, respectively. In the system, the ion mass was analyzed by a quadrupole and detected by a Faraday collector.

The films were deposited on silicon (100) wafers. Before deposition the wafers were chemically cleaned and submitted to rf sputter etching in $\mathrm{Ar}\left(P_{\mathrm{Ar}}=3 \times 10^{-1} \mathrm{~Pa}\right.$, power $=300 \mathrm{~W}$ ) for $7 \mathrm{~min}$. The base pressure inside the chamber was always below $8 \times 10^{-5} \mathrm{~Pa}$, achieved with a turbomolecular pump of $1500 \mathrm{l} / \mathrm{s}$ pumping speed. The Al $99.999 \%$ target $\left(7 \times 17 \mathrm{~cm}^{2}\right)$ was submitted to presputtering in an Ar ambient $\left(P_{\mathrm{Ar}}=3 \times 10^{-1} \mathrm{~Pa}\right.$, dc power $=200$ W) for $50 \mathrm{~min}$ to remove the $\mathrm{Al}_{2} \mathrm{O}_{3}$ layer prior to aluminum nitride deposition. The dc power supply was used to deposit the $\mathrm{AlN}_{x}$ films. During the process the incident power was kept constant. Dividing the incident power by the target area we obtain the power density, which is the usual parameter for comparing results obtained in different sputtering apparatuses. The plasma composition varied from one deposition set to the other but it was always composed by Ar- $\mathrm{N}_{2}$ mixtures (see Table I). To obtain films with homogeneous concentrations we kept the shutter closed in the first $5 \mathrm{~min}$ of deposition and only afterwards we started the deposition on the substrates, which lasted $1 \mathrm{~h}$ in most cases. To obtain the deposition rates of Table I we divided the thickness of the films by their corresponding deposition times. During deposition we could follow the process monitoring the partial and total pressures, the voltage, current, and power.

The aluminum nitride films were analyzed by nuclear reaction analyses (NRA) and Rutherford backscattering
TABLE I. Aluminum nitride deposition parameters by dc magnetron reactive sputtering and thin-film stoichiometries.

\begin{tabular}{cccccc}
\hline $\begin{array}{c}\text { Sample } \\
\text { no. }\end{array}$ & $\begin{array}{c}P_{\text {tot }} \\
\left(\times 10^{-1} \mathbf{P a}\right)\end{array}$ & $\begin{array}{c}\mathrm{N}_{2} \text { concentration } \\
\text { in plasma }(\%)\end{array}$ & $\begin{array}{c}\mathrm{dc} \text { power } \\
(\mathrm{W})\end{array}$ & $\begin{array}{c}\text { Deposition } \\
\text { rate }(\AA / \mathrm{A})\end{array}$ & $\begin{array}{c}\text { N/Al } \\
\text { in film }\end{array}$ \\
\hline 1 & 3 & 67 & 290 & 1.08 & 0.88 \\
2 & 3 & 67 & 430 & 1.83 & 0.86 \\
3 & 3 & 67 & 570 & 2.55 & 0.74 \\
4 & 3 & 57 & 290 & 1.44 & 0.86 \\
5 & 3 & 57 & 430 & 2.02 & 0.77 \\
6 & 3 & 57 & 570 & 2.67 & 0.73 \\
7 & 3 & 7 & 290 & $>12^{\mathrm{a}}$ & 0.39 \\
8 & 3 & 7 & 430 & $>12^{\mathrm{a}}$ & 0.36 \\
9 & 3 & 7 & 570 & $>12^{\mathrm{a}}$ & 0.35 \\
10 & 4 & 80 & 400 & 1.58 & 0.83 \\
11 & 4 & 75 & 230 & 0.56 & 0.88 \\
12 & 3 & 73 & 280 & 0.98 & 0.88 \\
13 & 3 & 67 & 230 & 0.65 & 0.88 \\
14 & 3 & 33 & 240 & 1.67 & 0.87 \\
15 & 3 & 17 & 240 & 6.67 & 0.77 \\
16 & 3 & 10 & 240 & 7.22 & 0.56 \\
\hline \hline
\end{tabular}

The aluminum peak width in the RBS spectrum is greater than the total interval of energy measured in the present experimental setup, indicating that the film has a thickness greater than $14400 \AA$, corresponding to a deposition time of $20 \mathrm{~min}$ in this specific case.

spectrometry (RBS). Some of the reactions used were the ${ }^{14} \mathrm{~N}(d, p){ }^{15} \mathrm{~N}$ and the ${ }^{16} \mathrm{O}(d, p){ }^{17} \mathrm{O}$ with incident deuterons of $610 \mathrm{keV} .{ }^{17}$ These reactions have a plateau in the excitation curve allowing us to extract the total amount of ${ }^{14} \mathrm{~N}$ in the thin films and to determine the contamination level of ${ }^{16} \mathrm{O}$. In the spectrum of the detected protons the areas under the peaks were compared to the ones obtained from convenient standards with known concentrations of ${ }^{14} \mathrm{~N}$ and ${ }^{16} \mathrm{O}$ and transformed to stoichiometric ratios. The other reactions we used were the ${ }^{14} \mathrm{~N}(p, \gamma){ }^{15} \mathrm{O}$ and the ${ }^{27} \mathrm{Al}(p, \gamma){ }^{28} \mathrm{Si}$, occurring, respectively, at 278 and 326 $\mathrm{keV},{ }^{18}$ both having narrow (width $\sim 1 \mathrm{keV}$ ) resonant peaks in the excitation curve allowing us to profile the depth concentration of these elements in the film. The $\gamma$ ray yield at each incident proton energy could be converted to the concentration of ${ }^{27} \mathrm{Al}$ or ${ }^{14} \mathrm{~N}$ atoms in a thin slab at a certain depth in the film. This conversion was made using the $\gamma$-ray yields of convenient standards (pure $\mathrm{Al}$ and AlN), estimating the densities of the films and the stopping power of protons in these films. The ${ }^{12} \mathrm{C}$ contamination could be checked out by the ${ }^{12} \mathrm{C}(d, p){ }^{13} \mathrm{C}$ reaction at 610 $\mathrm{keV}$.

The RBS (Ref. 19) was accomplished with incident $\alpha$ particles of $2 \mathrm{MeV}$. The experimental spectra were fitted using the RUMP code, ${ }^{20}$ where we assumed a density of 3.26 $\mathrm{g} / \mathrm{cm}^{3}$ for the films during the calculations. The stoichiometric ratios $\mathrm{N} / \mathrm{Al}$ thus obtained were compared to the ones obtained from NRA. The thicknesses of the films extracted from the RBS fittings were compared to the ones obtained via profilometer measurements. All data agreed within an error of $5 \%$.

\section{RESULTS AND DISCUSSION}

\section{A. Sputtering deposition parameters}

In an attempt to compare the present results with the ones from the literature we took the graphs of the cathode 

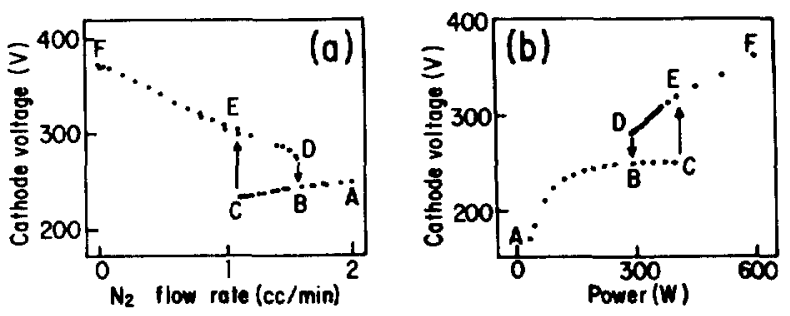

FIG. 1. (a) Cathode voltage vs nitrogen flow rate. The power is held at $295 \mathrm{~W}$. (b) Cathode voltage vs power. The nitrogen flow rate is held at $1.50 \mathrm{~cm}^{3} / \mathrm{min}$. Reproduced from Ref. 13 with permission.

voltage versus nitrogen flow rate at constant power and of the cathode voltage versus power at constant nitrogen flow from the article by McMahon and co-workers ${ }^{15}$ (Fig. 1). In Fig. 1(a), starting with a pure Al target, we can see the linear decrease of voltage with the increase of $\mathrm{N}_{2}$ flow rate from $F$ to $D$ and then a sudden voltage drop to $B$. At this point we already have the formation of nitride on the target surface. By decreasing the $\mathrm{N}_{2}$ flow an opposite transition is observed from $\mathbf{C}$ to $\mathbf{E}$ leading to a hysteresis loop DBCE. The reverse situation, starting with a target covered by aluminum nitride, is seen in Fig. 1(b), which also presents a hysteresis. In our case we controlled the $\mathrm{N}_{2}$ partial pressure and made a graph of the voltage versus $P_{\mathrm{N}_{2}}$ at constant power [240 W, Fig. 2(a)] and, controlling the incident power, made a graph of the voltage versus power at constant $\mathrm{N}_{2}$ and Ar partial pressures [Fig. 2(b)]. Comparing Figs. 1(a) and 2(a) we can see that the shapes of the curves are different but the hysteresis is present in both cases. However, the comparison between Figs. 1(b) and 2(b) evidences much greater modifications: The curve with a hysteresis obtained at constant $\mathrm{N}_{2}$ flow [Fig. 1(b)] be-

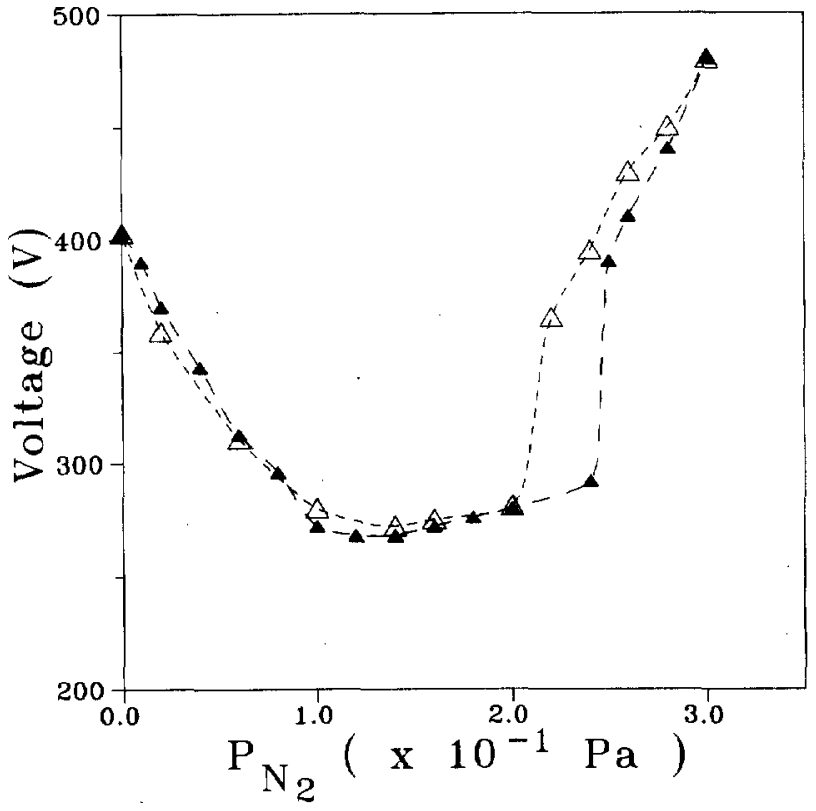

FIG. 3. Cathode voltage vs nitrogen partial pressure. The power is held at $480 \mathrm{~W}$. ( $\triangle$ ) represent experimental points obtained when we increase the nitrogen partial pressure while $(\Delta)$ show the path followed when the nitrogen partial pressure is decreased.

comes a straight line with no hysteresis at all, in the graph of the cathode voltage versus the dc power at constant $\mathbf{N}_{2}$ partial pressure [Fig. 2(b)]. Although the absence of hysteresis had already been observed, ${ }^{15}$ from our knowledge this linear behavior had not yet been reported.

In Fig. 3 we can see the analog of Fig. 2(a) but now at a greater $\mathrm{dc}$ power $(480 \mathrm{~W})$. The curves resemble each
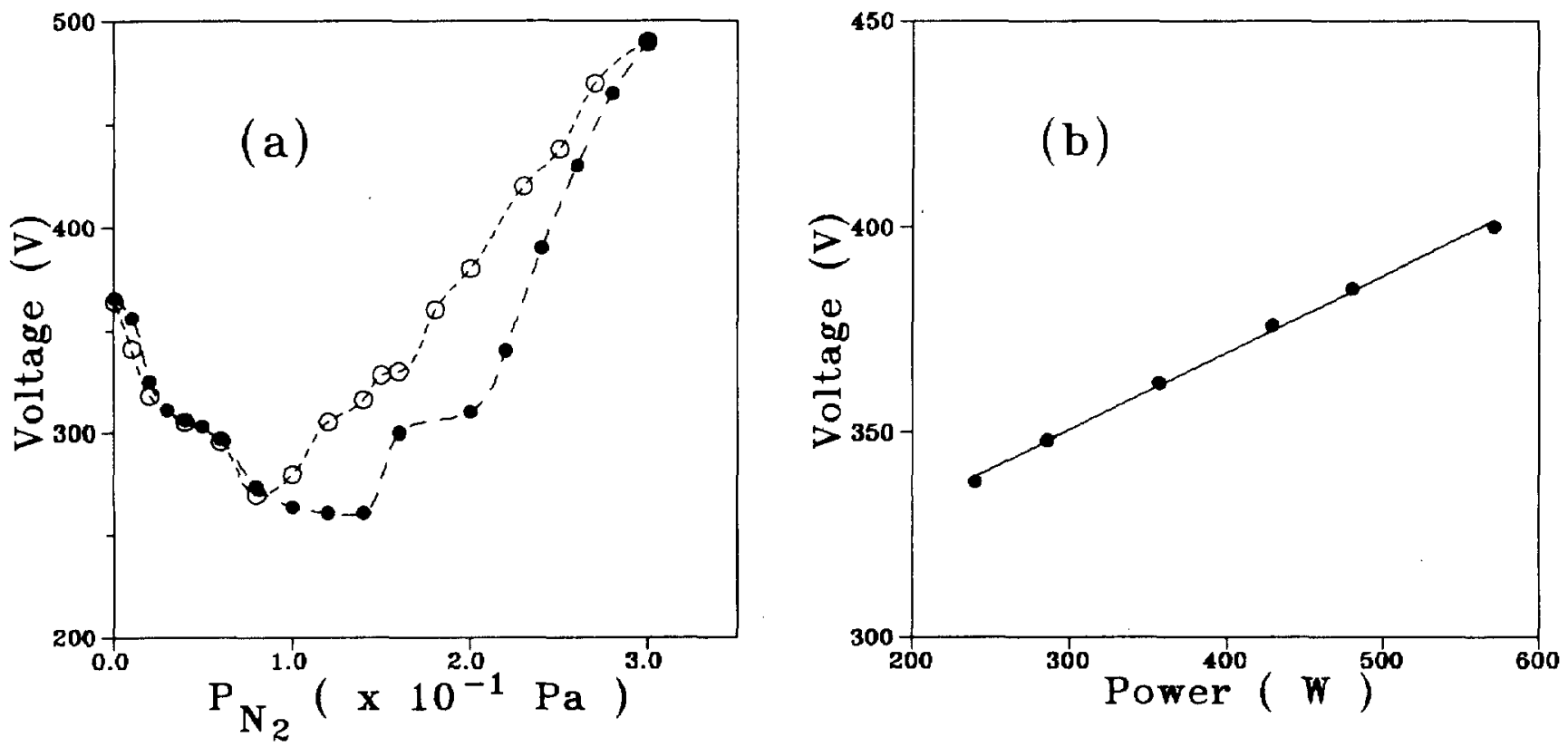

FIG. 2. (a) Cathode voltage vs nitrogen partial pressure. The power is held at $240 \mathrm{~W}$. ( $)$ ) represent experimental points obtained when we increase the nitrogen partial pressure, while $(O)$ show the path followed when the nitrogen partial pressure is decreased. (b) Cathode voltage vs power. The nitrogen partial pressure is held at $0.2 \times 10^{-1} \mathrm{~Pa}$ and the argon partial pressure at $2.8 \times 10^{-1} \mathrm{~Pa}$. 

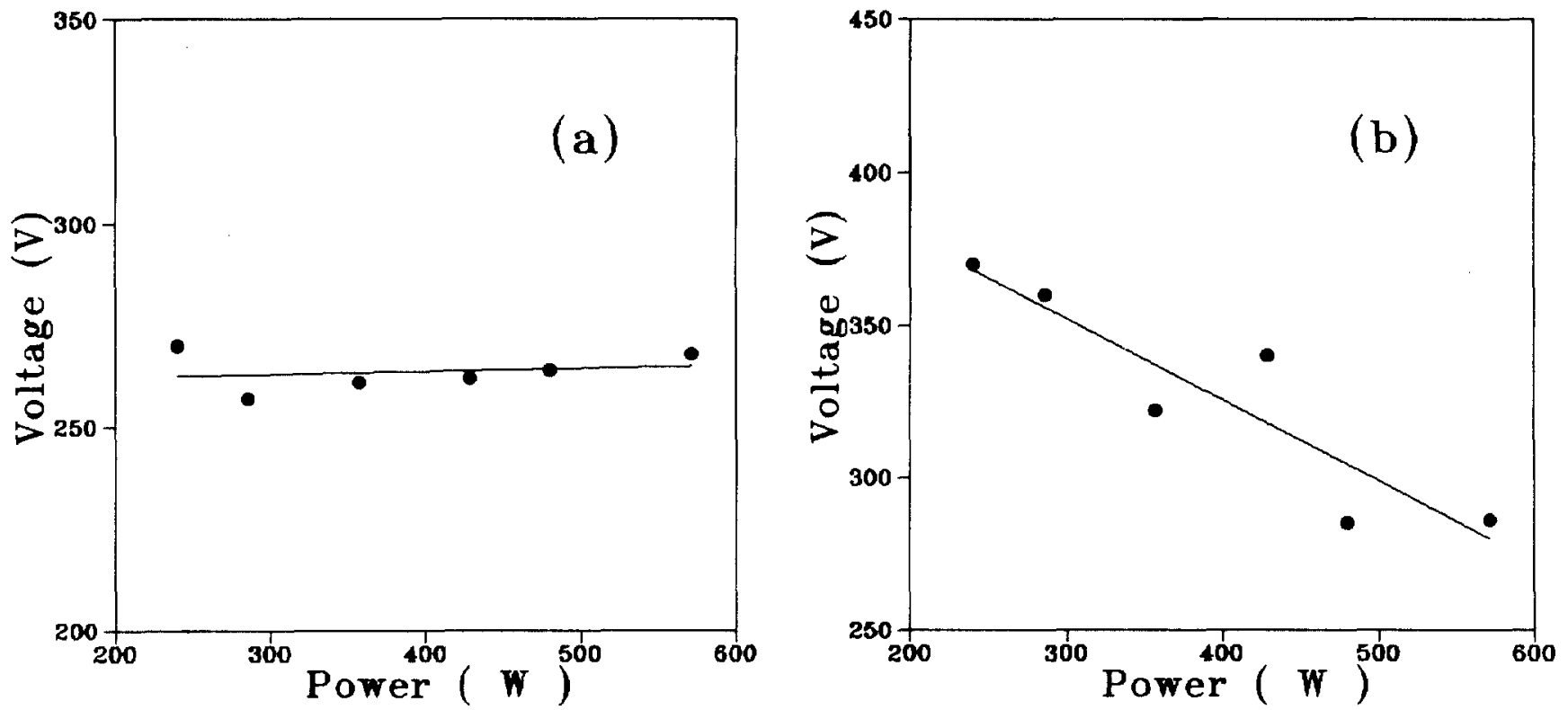

FIG. 4. Cathode voltage vs power. (a) The nitrogen partial pressure is held at $1.7 \times 10^{-1} \mathrm{~Pa}$ and the argon partial pressure at $1.3 \times 10^{-1} \mathrm{~Pa}$. (b) The nitrogen partial pressure is held at $2.0 \times 10^{-1} \mathrm{~Pa}$ and the argon partial pressure at $1.0 \times 10^{-1} \mathrm{~Pa}$.

other in shape, including the presence of the hysteresis loop, but we can see that the point at which the nitride formation starts is now shifted to higher $\mathrm{N}_{2}$ partial pressures. This result can be understood if we remember that at greater incident powers the sputtering rate is also greater and the formation of the nitride on the target will demand greater nitrogen concentrations in the plasma.

Modifications in the $\mathbf{N}_{2}$ concentration in the plasma lead to changes in the slope of the straight lines obtained in the graphs of the cathode voltage versus power as shown in Figs. 2(b), 4(a), and 4(b). From these figures we can notice that as we increase the $\mathrm{N}_{2}$ partial pressure in the chamber the slope of the straight line decreases, passes through zero, and becomes negative.

\section{B. NRA and RBS analysis}

Based on the study of the sputtering parameters we deposited aluminum nitride thin films under the different conditions displayed in Table $\mathbf{I}$. These films were analyzed by RBS and NRA. In Fig. 5 we can see typical RBS spectra of aluminum nitride films deposited on $\mathrm{Si}(100)$ wafers. This set of films (samples 1-3 in Table I) was obtained at the same $\mathrm{N}_{2}$ and Ar partial pressures and deposition times, but at different incident dc powers. One of the results is that the thickness of the aluminum nitride films is increased as the dc power is increased. In the graph such behavior can be observed by the shift to lower energies of the peak corresponding to the position of the interface between the aluminum nitride film and the silicon substrate. In fact, these peaks correspond to the superposition of the aluminum signal and the silicon one at this interface.

In Fig. 6 are shown the deexcitation peaks obtained by the incidence of $610 \mathrm{keV}$ deuterons. The area under the ${ }^{14} \mathrm{~N}_{p_{5}}$ signal was the one used to evaluate the amount of nitrogen in the film. The ${ }^{16} \mathrm{O}_{p_{1}}+{ }^{14} \mathrm{~N}_{p_{6}}$ and ${ }^{16} \mathrm{O}_{p_{0}}$ peaks exhibit the effect of the presputtering time of the target with respect to the oxygen content of the films. The solid curve was obtained from an aluminum nitride film deposited after a presputtering of the Al target for $30 \mathrm{~min}$ $\left(P_{\mathrm{Ar}}=3 \times 10^{-1} \mathrm{~Pa}\right.$, power $\left.=200 \mathrm{~W}\right)$, while the dotted curve was obtained from a film deposited after $50 \mathrm{~min}$ of presputtering. The analysis of the above-mentioned ${ }^{14} \mathrm{~N}$ and ${ }^{16} \mathrm{O}$ peaks in Fig. 6 led to an $\mathrm{O} / \mathrm{N}$ ratio of 0.03 for the aluminum nitride film that was deposited after $50 \mathrm{~min}$ of presputtering (sample 10 in Table I), whereas for the aluminum nitride sample that was deposited after 30 min of presputtering the $\mathrm{O} / \mathrm{N}$ ratio extracted from the figure was 0.08 . It is noteworthy that these two samples had the same $\mathrm{N} / \mathrm{Al}$ ratio, namely 0.83 . We can conclude from these re-

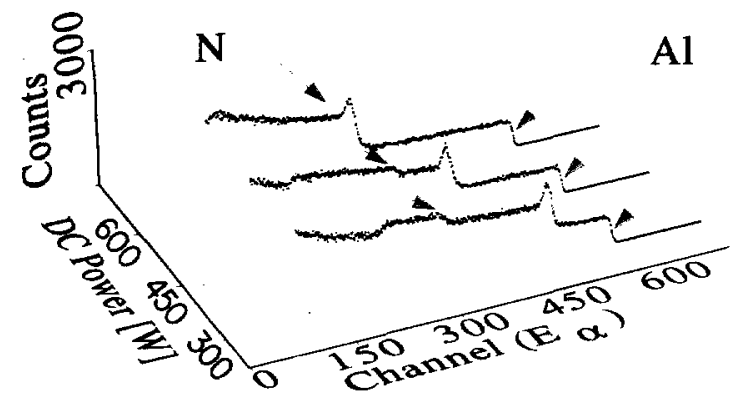

FIG. 5. RBS spectra obtained with $2.0 \mathrm{MeV}$ incident $\alpha$-particles backscattered by aluminum nitride thin films deposited on $\mathrm{Si}(100)$ at three different dc powers, namely 290,430 , and $570 \mathrm{~W}$. The incident and detection angles were $0^{\circ}$ and $160^{\circ}$ to the substrate normal, respectively. The arrows indicate the energy edges of the aluminium and nitrogen signals at the outermost surface. The highest peaks come from the superposition of the aluminium and the silicon signals at the film-substrate interfaces. 


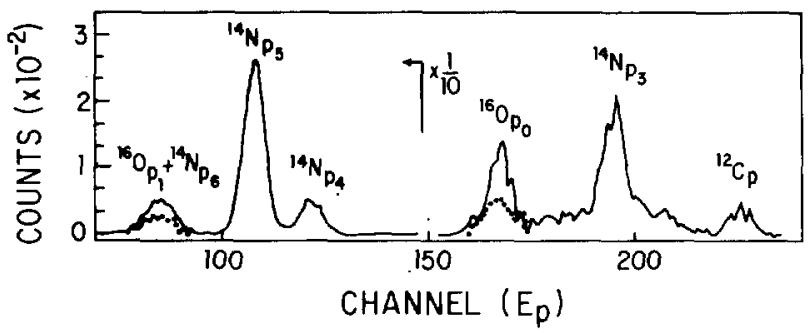

FIG. 6. Spectra of the detected protons resulting from the incidence of 610 $\mathrm{keV}$ deuterons on an aluminium nitride thin film. The protons coming from different excited states are indexed in the figure. The solid line spectrum came from a film deposited after $30 \mathrm{~min}$ of presputtering of the aluminium target. The dotted curves came from a film deposited after 50 min of presputtering of the target.

sults that a presputtering of at least $50 \mathrm{~min}(200 \mathrm{~W})$ is necessary to remove all aluminum oxide formed in the $\mathrm{Al}$ target surface. Furthermore, the carbon contamination is seen, from Fig. 6, to be very small in both samples, independently of the presputtering time.

The $(p, \gamma)$ resonances in ${ }^{14} \mathrm{~N}$ and ${ }^{27} \mathrm{Al}$ were made sequentially, since the first one occurs with protons of 278 $\mathrm{keV}$ and the second one with protons of $326 \mathrm{keV}$. With these resonances it was possible to obtain the ${ }^{14} \mathrm{~N}$ and ${ }^{27} \mathrm{Al}$ depth profiles of the aluminum nitride thin films. The linewidths of the $(p, \gamma)$ resonances are 1.6 and $<1 \mathrm{keV}$ respectively, so they are both rather close to the resolution in energy of the proton beam (about $1 \mathrm{keV}$ ). Using the calculated stopping powers for protons in AIN at the threshold energies of the corresponding $(p, \gamma)$ reactions we obtained depth resolutions of about $200 \AA$ in the profiles. Observing Fig. 7 we see that, as the incident energy of protons is increased, the normalized area under the $\gamma$ peaks ("Counts," in the graph) is proportional to the concentration of $\mathrm{N}$ (at lower energies) and $\mathrm{Al}$ (at higher energies)

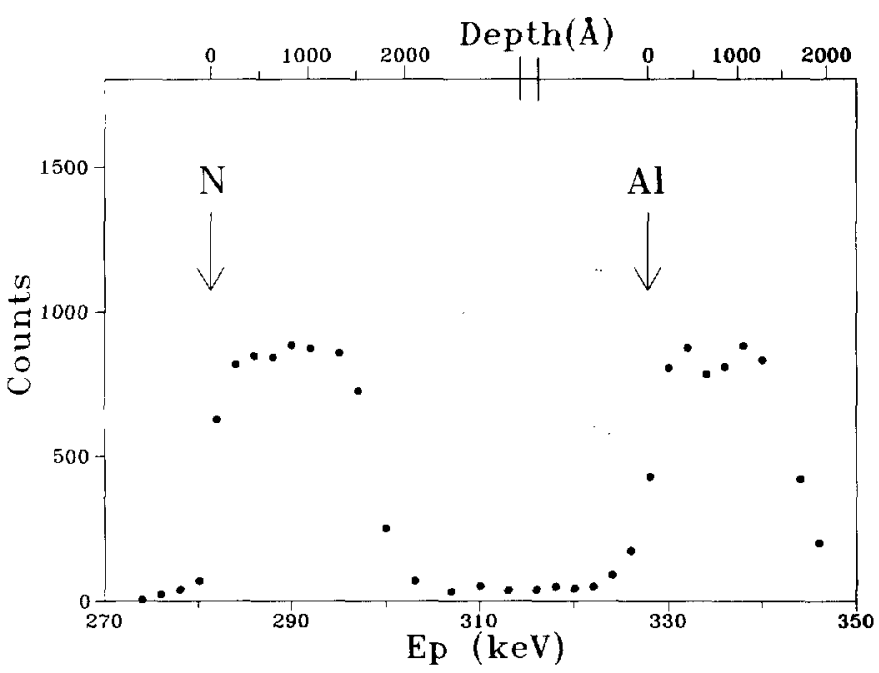

FIG. 7. Nitrogen and aluminium depth profiles obtained, respectively, from the ${ }^{14} \mathrm{~N}(p, \gamma)$ and ${ }^{27} \mathrm{Al}(p, \gamma)$ resonances of an aluminium nitride thin film. The arrows indicate the outermost edges of the film in the nitrogen and aluminium depth profiles. in layers at increasing depths in the film. This figure shows the profiles of the sample 11 in Table I: an $\mathrm{AlN}_{0.88}$ film of $2000 \AA$.

\section{Relationships between deposition parameters and films characteristics}

Samples 1-9 in Table I were deposited in order to clarify the behavior displayed in Figs. 2(b), 4(a), and 4(b). Argon and nitrogen partial pressure sets were chosen $\left(P_{\mathrm{N}_{2}}=0.2 \times 10^{-1}\right.$ and $P_{\mathrm{Ar}}=2.8 \times 10^{-1} \mathrm{~Pa} ; P_{\mathrm{N}_{2}}=1.7$ $\times 10^{-1}$ and $P_{\mathrm{Ar}}=1.3 \times 10^{-1} \mathrm{~Pa} ; P_{\mathrm{N}_{2}}=2.0 \times 10^{-1}$ and $\left.P_{\mathrm{Ar}}=1.0 \times 10^{-1} \mathrm{~Pa}\right)$ and the films were deposited at three different powers, namely 290,430 , and $570 \mathrm{~W}$. The stoichiometric ratios of such films show that as the power was increased, at constant nitrogen concentration in the plasma, the stoichiometric ratio N/Al showed a slight decrease. This is due to the linear increase, under the same conditions, of the deposition rate or, in other words, of the sputtering rate. When the power is increased a greater sputtering rate takes place at the target. If the concentration of $\mathrm{N}_{2}$ is kept constant the consequence is that more $\mathrm{Al}$ atoms are sputtered from the target due to the increase on the power, but these $\mathrm{Al}$ atoms will share the same amount of nitrogen atoms available to react, leading to a decrease in the N/Al stoichiometric ratio of the aluminum nitride film. Concerning the general content of nitrogen in these films, we can see that the films deposited at $P_{\mathrm{N}_{2}}=2.0 \times 10^{-1} \mathrm{~Pa}$ or $67 \%$ of $\mathrm{N}_{2}$ in plasma and at $P_{\mathrm{N}_{2}}=1.7 \times 10^{-1} \mathrm{~Pa}$ or $57 \%$ of $\mathrm{N}_{2}$ in plasma present stoichiometric ratios lying in the region between $\mathrm{N} / \mathrm{Al}=0.73$ and $\mathrm{N} / \mathrm{Al}=0.88$, this last value being already in the saturation region. The films deposited at $P_{\mathrm{N}_{2}}=0.2 \times 10^{-1} \mathrm{~Pa}$ or $7 \%$ of $\mathrm{N}_{2}$ in plasma, however, exhibit a nitrogen content much lower then the above-mentioned ones.

The smaller the percentage of $\mathrm{N}_{2}$ in the plasma the more stable is this plasma. This statement is confirmed by the spread of the experimental points around the straight lines in Figs. 2(b), 4(a), and 4(b) and by visual observation of the plasma which starts presenting some sparks when the $\mathbf{N}_{2}$ partial pressure is increased.

As general observations from Table I we can see that at a constant power, an increase in the $\mathrm{N}_{2}$ content in the plasma produces aluminum nitride films richer in nitrogen (see, for example, samples 14, 15, and 16). This behavior can be observed until a saturation point is reached (about $40 \%$ of $\mathrm{N}_{2}$ in the plasma, for a power of $240 \mathrm{~W}$ ), when films slightly hypostoichiometric $(\mathrm{N} / \mathrm{Al}=0.88$ and not $\mathrm{N} / \mathrm{Al}=1$ ) are obtained. On the other hand, if we maintain the $\mathrm{N}_{2}$ concentration fixed in the plasma and increase the incident power, the nitrogen content in the films decreases as we can observe in samples 4-6, for example. The dependence of the deposition rates on the nitrogen partial pressure indicates a situation, at lower nitrogen partial pressures, with a high deposition rate (samples 7-9, for example) characteristic of a metallic target and another one, at greater nitrogen partial pressures, with a lower deposition rate (samples 11-13, for example) characteristic of a partially or totally nitrided target. In between there is a rapid transition that occurs at about $20 \%$ of $\mathrm{N}_{2}$ in the 
plasma for a power of $240 \mathrm{~W}$ or a power density of 2.0 $\mathrm{W} \mathrm{cm}^{-2}$. This behavior was already observed by other authors. Aita and Gawlak ${ }^{21}$ deposited aluminum nitride films by rf reactive sputtering varying the power density from 0.6 to $0.8 \mathrm{~W} \mathrm{~cm}^{-2}$ when the $\mathrm{N}_{2}$ content was increased from $0 \%$ to $100 \%$. Nevertheless, they also found the transition region at about $20 \%$ of nitrogen in plasma in the graph of the growth rate versus the percentage of $\mathrm{N}_{2}$. Svub and Musil ${ }^{22}$ deposited AlN $_{x}$ films by dc magnetron reactive sputtering, as in the present work, and also found the above-mentioned transition region at about $20 \%$ nitrogen in plasma using a power density of $11.5 \mathrm{~W} \mathrm{~cm}^{-2}$.

\section{SUMMARY AND CONCLUSIONS}

In the study of the dc magnetron reactive sputtering we established correlations among the deposition parameters cathode voltage, $\mathrm{N}_{2}$ and Ar partial pressures, and incident power and compared them to the ones reported in the literature. As new aspects we should mention the linear behavior, without hysteresis, that we found between the cathode voltage and the power at constant $\mathrm{N}_{2}$ and $\mathrm{Ar}$ partial pressures and the dependence of the slope of the straight line on the percentage of $\mathrm{N}_{2}$ in the plasma.

Concerning the analytical tools we used, we should emphasize the usefulness of the $(d, p)$ reactions, since at once we obtain the total ${ }^{14} \mathrm{~N}$ content in the film and determine its contamination level with ${ }^{16} \mathrm{O}$ and ${ }^{12} \mathrm{C}$. On the other hand, the $(p, \gamma)$ reactions provide sequential depth profiles of the elements ${ }^{14} \mathrm{~N}$ and ${ }^{27} \mathrm{Al}$, besides of an absolute measurement of the stoichiometric ratio, when we use a pure $\mathrm{Al}$ sample as a standard for the last reaction.

We noticed that two main factors compete in modifying the sputtering rate, the deposition rate, and the stoichiometric ratio N/Al of the films: These factors are the incident power during deposition and the percentage of $\mathrm{N}_{2}$ in the plasma. The greater the incident power, at constant $\mathbf{N}_{2}$ and Ar partial pressures, the greater are the sputtering and the deposition rates and the smaller is the N/Al ratio in the film. On the other hand, the greater the percentage of $\mathrm{N}_{2}$ in the plasma, at constant power, the smaller are the sputtering and the deposition rates and the greater is the N/Al ratio in the film. However, these dependencies are not linear; they exhibit a saturation behavior at higher percentages of $\mathbf{N}_{2}$ in the plasma. Aware of these correlations, it is now possible to deposit $\mathbf{A l N}_{x}$ films with predetermined stoichiometries.

\section{ACKNOWLEDGMENTS}

We would like to express our gratitude to Professor Dr. Ruth S. Schneider for the fruitful discussions we had and for her helpful hints. This work was supported in part by CNPq, Brazil.

${ }^{1}$ T. Shiosaki, T. Yamamoto, T. Oda, and A. Kawabata, Appl. Phys. Lett. 36, 643 (1980).

${ }^{2}$ A. Fathimula and A. A. Lakhani, J. Appl. Phys. 54, 4586 (1983).

${ }^{3}$ S. Okamura, H. Nishi, T. Inada, and H. Hashimoto, Appl. Phys Lett. 40, 689 (1982)

${ }^{4}$ R. G. Gordon, D. M. Hoffman, and U. Riaz, J. Mater. Res. 6, 5 (1991).

${ }^{5}$ G. A. Nyberg and R. A. Buhrman, J. Vac. Sci. Technol. A 2, 301 (1984).

${ }^{6} S$. Yoshida, S. Misawa, Y. Fujii, S. Takada, H. Hayakawa, S. Gonda, and A. Itoh, J. Vac. Sci. Technol. 16, 990 (1979).

${ }^{7}$ Y. Murayama and K. Kashiwagi, J. Vac. Sci. Technol. 17, 796 (1980). ${ }^{8}$ I. Kanno, K. Nomoto, S. Nishijima, T. Nishiura, T. Okada, K. Katagiri, H. Mori, and K. Iwamoto, Nucl. Instrum. and Methods B 59/60, 920 (1991).

${ }^{9}$ K. Ogata, Y. Andoh, and E. Kamijo, Nucl. Instrum. Methods B 39, 178 (1989).

${ }^{10}$ J. M. E. Harper, J. J. Cuomo, and H. T. G. Hentzell, J. Appl. Phys. 58, 550 (1985).

"IJ. J. Hantzpergue, Y. Pauleau, J. C. Remy, D. Roptin, and M. Cailler, Thin Solid Films 75, 167 (1981).

${ }^{12}$ S. Berg, H.-O. Blom, T. Larsson, and C. Nender, J. Vac. Sci. Technol. A 5, 202 (1987).

${ }^{13}$ S. Maniv and W. D. Westwood, J. Vac. Sci. Technol. 17, 743 (1980).

${ }^{14}$ S. Maniv and W. D. Westwood, J. Vac. Sci. Technol. 18, 195 (1981).

${ }^{15}$ R. McMahon, J. Affinito, and R. R. Parsons, J. Vac. Sci. Technol. 20, 376 (1982).

${ }^{16}$ J. Affinito and R. R. Parsons, J. Vac. Sci. Technol. A 2, 1275 (1984).

${ }^{17}$ M. Berti and A. V. Drigo, Nucl. Instrum. Methods 201, 473 (1982).

${ }^{18}$ F. C. Stedile, R. Hübler, I. J. R. Baumvol, W. H. Schreiner, and F. L. Freire, Jr., Nucl. Instrum. and Methods B 64, 756 (1992).

${ }^{19}$ W. K. Chu, J. M. Mayer and M.-A. Nicolet, Backscattering Spectrometry (Academic, New York, 1978).

${ }^{20}$ L. R. Doolittle, Nucl. Instrum. Methods B 9, 344 (1985).

${ }^{21}$ C. R. Aita and C. J. Gawlak, J. Vac. Sci. Technol. A 1, 403 (1983).

${ }^{22}$ J. Švub and J. Musil, Czech. J. Phys. B 35, 1191 (1985). 